\title{
Anxiety symptoms prior to a prostate cancer diagnosis: Associations with knowledge and openness to treatment
}

\author{
Amanda J. Dillard ${ }^{1}$, Laura D. Scherer ${ }^{2}$, Peter A. Ubel ${ }^{3}$, \\ Stewart Alexander ${ }^{4}$ and Angela Fagerlin ${ }^{5,6}$ \\ 'Department of Psychology, Grand Valley State University, Allendale, Michigan, USA \\ ${ }^{2}$ Department of Psychological Sciences, University of Missouri, Columbia, Missouri, \\ USA \\ ${ }^{3}$ Fuqua School of Business and Sanford School of Public Policy, Duke University, \\ Durham, North Carolina, USA \\ ${ }^{4}$ Department of Consumer Science, Purdue University, West Lafayette, Indiana, USA \\ ${ }^{5}$ Departments of Internal Medicine and Psychology, Ann Arbor VA Center for Clinical \\ Management Research, Michigan, USA \\ ${ }^{6}$ Center for Bioethics and Social Sciences in Medicine, University of Michigan, Ann \\ Arbor, Michigan, USA
}

Aim. Research suggests that anxiety may be a common response to a cancer diagnosis, but research is needed to examine anxiety before diagnosis. Anxiety before diagnosis may relate to the comprehension of relevant health information or openness to potential treatments. This study examined anxiety and these outcomes in men who were waiting to learn of a prostate cancer diagnosis.

Objectives. One goal of this study was to determine whether anxiety would increase as men came closer to learning the results of their prostate cancer biopsy. Another goal was to test whether anxiety was associated with knowledge about prostate cancer or openness to different treatments.

Methods. Men $(N=265)$ who were facing a prostate cancer diagnosis were surveyed at two time points. Time I occurred at the time of biopsy, and Time 2 occurred immediately before men received their biopsy result. At each time point, men reported their anxiety about prostate cancer and their biopsy result. At Time 2, they completed a knowledge test of information about prostate cancer and reported their openness to different potential treatments.

Results. Anxiety symptoms increased as men came closer to learning their diagnosis. Also, higher anxiety was associated with lower knowledge and greater openness to particular treatments like surgery. Interactions showed that when anxiety increased from Time I to Time 2, having high or low knowledge mattered less to treatment openness.

Conclusion. Waiting for a cancer diagnosis is an important time period in which anxiety may increase and relate to information processing and openness to treatments.

*Correspondence should be addressed to Amanda J. Dillard, Department of Psychology, Grand Valley State University, Allendale, MI 4940I, USA (email: dillaram@gvsu.edu). 


\section{Statement of contribution}

What is already known on this subject?

- Men undergoing prostate cancer screening have been found to experience high and low levels of anxiety.

- Research has shown that negative emotions like anxiety are common following a cancer diagnosis, but little research has examined emotions right before diagnosis.

- Anxiety has been associated with information processing and motivation to engage in preventive behaviours.

\section{What does this study add?}

- Applies and tests a theoretical idea related to how anxiety may change as one approaches personally relevant threatening health feedback.

- Shows relationships between changes in anxiety and knowledge in the context of waiting for actual health feedback.

- Associates increased anxiety in the prostate cancer context with knowledge and openness to different treatments.

Every day thousands of people wait for information about their health. The information may range from mild ('you have a cold') to severe ('you have cancer'). While many people may experience some uncertainty while they wait for this information, those waiting for serious diagnoses may experience great distress. For example, research shows that the 'waiting game' for cancer diagnoses is associated with the experience of intense distress including negative emotions like anxiety (e.g., Awsare et al., 2008; Maxwell et al., 2000; Saegrov \& Halding, 2004; Scott, 1983; Thorne, Harris, Hislop, \& Vestrup, 1999). Although this distress has been documented, we know little about its course (Poole, 1997). For example, as people wait, do they increase in distress? Moreover, how might distress relate to other events during this time, like the processing of relevant health information? In this study, we investigate these questions in men who were waiting to learn of a prostate cancer diagnosis.

When people receive a cancer diagnosis, research shows they experience a flood of negative emotions with anxiety being particularly prevalent (Burgess et al., 2005; Edwards \& Clarke, 2004; Hughes, 1982; Linden, Vodermaier, MacKenzie, \& Greig, 2012; Saegrov \& Halding, 2004; Stanton \& Snyder, 1993; Stark \& House, 2000; van't Spijker, Trijsburg, \& Duivenvoorden, 1997). While this research has examined negative emotions like anxiety after a diagnosis, research is needed to examine these emotions before a diagnosis. The phase right before a cancer diagnosis is important because it can be one of high anxiety (e.g., Maxwell et al., 2000; Saegrov \& Halding, 2004; Scott, 1983; Thorne et al., 1999), with even higher levels than compared to after a diagnosis (Dale, Bilir, Han, \& Meltzer, 2005; Fantini-Hauwel, Dauvier, Arciszewski, Antoine, \& Manouvrier, 2011; Liao, Chen, Chen, \& Chen, 2008). Assessing emotions like anxiety before diagnosis is also important because it may relate to individuals' processing and comprehension of relevant information. For example, in the area of breast cancer, one study found that increased cancer anxiety was related to biased information processing in women who had a high risk of the disease but were not yet diagnosed (Cameron \& Reeve, 2006). This information processing could have effects on actual decisions one makes after a diagnosis (Denberg, Melhado, \& Steiner, 2006). 


\section{Anxiety in prostate cancer diagnoses}

Relative to diagnoses of breast cancer, there has been much less research on anxiety in people facing diagnoses of prostate cancer (Dale et al., 2005). The prostate cancer context is uniquely important because this cancer is specific to males, and research reveals gender differences in levels of cancer-related worry and anxiety (e.g., McQueen, Vernon, Meissner, \& Rakowski, 2008). The research on anxiety in those facing prostate cancer diagnoses has also been mixed. For example, some studies have shown that men who are undergoing screening are no more anxious than men who have never participated in screening (e.g., Carlsson, Aus, Wessman, \& Hugosson, 2007; Essink-Bot et al., 1998). Little to no anxiety was found even in men who have an increased risk of prostate cancer or who have multiple screenings (Brindle et al., 2006; Carlsson et al., 2007; also see Wade et al., 2013). However, other research has painted a different picture (e.g., Gustafsson et al., 1995; Medd, Stockler, Collins, \& Lalak, 2005). Some studies have found that screening increases anxiety or that men avoid screening because they are worried they will be diagnosed with prostate cancer (Cormier et al., 2002; Roumier et al., 2004). In a review of the literature, Dale et al. (2005) concluded that there were generally high levels of anxiety in at-risk men (e.g., age of 50 years and a first-degree relative who had been diagnosed with prostate cancer) who were undergoing screening. This finding was observed whether anxiety was measured as a state, subclinical or clinical levels, or as worry.

Importantly, these empirical inconsistencies may relate to the problem of measuring anxiety at only one time point. In other words, researchers may assess individuals only at screening but then as they wait for their diagnoses, their anxiety changes. This idea would fit with predictions stemming from the model of uncertainty navigation, which offers insight into how people respond to threatening, but not yet known, information (Sweeny \& Cavanaugh, 2012). According to the model, as individuals approach uncertain, potentially threatening health information, they will increase in anxiety. Increases in anxiety may motivate bracing, a coping strategy in which individuals become more pessimistic in their expectations of the potentially threatening feedback (Shepperd, Grace, Cole, \& Klein, 2005; Sweeny \& Shepperd, 2007). To date, bracing has been investigated in mostly non-health domains (e.g., Shepperd, Ouellette, \& Fernandez, 1996; Sweeny \& Andrews, 2014) or hypothetical health domains (Taylor \& Shepperd, 1998). In the present study, we were not assessing bracing per se, but rather testing its underlying mechanism - that is, will anxiety increase as people come closer to receiving an actual threatening diagnosis?

To date, only a handful of studies have measured anxiety more than once as men wait for a prostate cancer diagnosis. Zisman, Leibovici, Kleinmann, Siegel, and Lindner (2001) assessed men's anxiety about biopsy at two time points before they learned their diagnosis. They found that anxiety peaked at the second time point, immediately before the men learned their results. Another study found that men's anxiety levels (as measured by the State-Trait Anxiety Inventory) before biopsy and then again right before they learned their results were similar with both being significantly higher than when they had decided to have a biopsy (Saraçoğlu, Ünsal, Taşkın, Sevinçok, \& Zafer Karaman, 2012). Two other studies have assessed whether clinical anxiety (using the Hospital Anxiety and Depression Scale) was present in men having biopsies (Awsare et al., 2008; Macefield et al., 2009). Although clinical anxiety was not present in either study (even for men with higher prostate-specific antigen [PSA] levels; Macefield et al., 2009), as men approached diagnosis, they were more likely to say waiting for results was the most stressful aspect of the biopsy process (Awsare et al., 2008). 
In the present study, we test the basic idea that men will increase in anxiety as they come closer to learning their cancer diagnosis. We measured anxiety in terms of the men's intrusive thoughts about prostate cancer and their fear about the biopsy result revealing cancer. Along with possibly replicating others' findings (e.g., Zisman et al., 2001), we extend the existing research by addressing the question of whether there may be associations with this anxiety. For example, when individuals undergo a screening process, they are given information about the screening test, the cancer, and available treatment options should they have cancer. How might anxiety be associated with the processing of this information? Historically, researchers have debated about how negative affective states influence information processing, with some experimental research showing it leads to more careful processing (e.g., Schwarz, 2000; Schwarz, Bless, \& Bohner, 1991), and others showing it leads to less careful processing (e.g., Conway \& Giannopoulos, 1993; Lewinsohn \& Mano, 1993; Raghunathan \& Pham, 1999). Unfortunately, this research has not examined specific negative emotions or actual health contexts. Of the few studies of this nature, evidence is growing to suggest that higher anxiety will be associated with lower attention and comprehension (e.g., Cameron \& Reeve, 2006; Lerman, Seay, Balshem, \& Audrain, 1995). In the present study, we examine whether anxiety is associated with participants' knowledge of information presented in a decision aid about prostate cancer. Examining this association in the context of waiting to learn of a cancer diagnosis would represent a novel contribution to research on negative emotions and information processing.

Along with information processing, anxiety may be associated with wanting to do particular cancer treatments. Generally, research supports the notion that when people feel worry or anxiety about cancer, they are motivated towards preventive action (e.g., Cameron \& Reeve, 2006; Dillard et al., 2013; McCaul, Schroeder, \& Reid, 1996), including prostate cancer screening (Consedine, 2012). Although in prostate cancer, there is no one 'best' treatment, some treatments may be perceived as more action-oriented. For example, surgery may be viewed as a more problem-focused approach while watchful waiting may be viewed as a more emotion-focused approach (Pickles, Ruether, Weir, Carlson, \& Jakulj, 2007). Related to this, research suggests that more invasive treatments for prostate cancer, like surgery, are preferred when people perceive internal and external pressure to 'fight' their cancer (Chapple et al., 2002). In the present study, if anxiety motivates an action-oriented approach to treatment, men who have more anxiety may evidence greater openness to a treatment like surgery and less openness to a treatment like watchful waiting.

\section{Overview and hypotheses}

In the present study, we examined men's symptoms of anxiety as they waited to learn whether they had prostate cancer. Symptoms of anxiety about prostate cancer and the biopsy result were assessed at two time points, both occurring before the men received a diagnosis of prostate cancer. We also examined whether anxiety at these two time points related to the men's knowledge of prostate cancer or their openness to different treatments. Based on the research described above, we had three hypotheses. First, we hypothesized that symptoms of anxiety would increase as men came closer to receiving their diagnosis. In other words, from Time 1 (i.e., having their biopsy) to Time 2 (i.e., right before they learned their biopsy result), men would significantly increase in anxiety. Second, we hypothesized a negative association between anxiety and knowledge. For example, at Time 2, men who had higher anxiety would have less knowledge of 
information we gave them about prostate cancer. Third, we hypothesized that anxiety may be associated with openness to particular treatments such that higher anxiety would be associated with a greater openness to surgery and a lower openness to watchful waiting.

Along with testing these three hypotheses, we also explored whether anxiety would interact with knowledge to influence openness to treatments. To date, anxiety has interacted with knowledge to influence behaviour intentions in two previous studies, both done in the context of breast cancer (Cameron \& Reeve, 2006; Dillard et al., 2013). Both studies suggested that when anxiety about cancer is high, individuals may be less likely to use knowledge to inform their behaviour intentions.

\section{Method}

\section{Participants}

Men $(N=1,552)$ facing a prostate cancer biopsy were approached to participate in this study. Of the 1,028 who agreed, 1,023 completed the Time 1 survey (99\%). Of this group, 334 men (33\%) were later diagnosed with localized prostate cancer and therefore eligible to complete the Time 2 survey. Of these men, 265 (79\%) completed the Time 2 survey which was just before they received their prostate cancer diagnosis from their physician, about 1 month ( $M=35.5$ days) after Time $1 .^{1}$

Of participants who received a diagnosis of prostate cancer, the average age was 63 years, 73\% were White/Caucasian (of which 2\% were Hispanic), 25\% were Black/ African American, and 2\% American Indian, Asian/Asian American, or of Middle Eastern origin. Approximately $18 \%$ of the men reported a family history of prostate cancer.

\section{Procedure}

Participants were recruited from four VA Health Systems: Ann Arbor, MI, Durham, NC, Pittsburgh, PA, and San Francisco, CA. Institutional review board approval was obtained from all places. Clinical coordinators at the different sites identified patients who were either going to learn about an elevated PSA level and need for a biopsy or were being biopsied. Men completed Time 1 at either an appointment with their urologist when they were told they needed a biopsy $(n=125)$ or at their actual biopsy appointment $(n=140){ }^{2}$ During reception, participants provided informed consent. They then reported their anxiety about prostate cancer and their test result. At this time point, participants were also randomized to receive one of two decision aids to take home. ${ }^{3}$ Approximately 1 month later, at Time 2, participants completed the anxiety measures again as well as measures that assessed their knowledge from the decision aid and openness to treatments. Immediately after the Time 2 survey, participants received their diagnosis result from their urologist. In exchange for participating, men received a $\$ 20$ gift card.

\footnotetext{
' Electronic medical records were used to learn diagnoses. Only those who had cancer returned for Time 2.

${ }^{2}$ Analyses were conducted to test whether participants who were completing the Time I survey at the urologist's office when learning a biopsy was needed versus those who were completing the survey at the time of biopsy differed in their baseline anxiety. Analyses showed no significant differences for intrusive thoughts, $\mathrm{Ms}=1.0 \mathrm{I}$ versus $I .02, \mathrm{~F}(\mathrm{I}, 263)=0.03, \mathrm{p}=\mathrm{ns}$, or testresult anxiety, $\mathrm{Ms}=0.88$ versus $I .05, \mathrm{~F}(I, 262)=1.72, \mathrm{p}=.19$.

${ }^{3}$ One aim of this overall project was to compare two decision aids [Fagerlin et al., 2015]. Both decision aids described localized prostate cancer, but they differed in literacy level, emphasis on shared decision-making, and inclusion of statistical information. When controlling for type of decision aid, the association between test-result anxiety and knowledge becomes marginal, $\beta=-. I I, \mathrm{t}=-1.68, \mathrm{P}=.09$. All of the other analyses remain the same as reported in the paper.
} 


\section{Measures}

\section{Anxiety symptoms}

To assess symptoms of anxiety about prostate cancer, we used five items that participants completed as part of the Memorial Anxiety Scale for Prostate Cancer (MAX-PC; Roth et al., 2003). The five items were combined to create a scale of intrusive thoughts. Intrusive thoughts represent unwanted and repetitive thoughts focused on a stressor or stressful event (Horowitz, 1986; Horowitz, Wilner, \& Alvarez, 1979). Many previous studies have used intrusive thoughts to measure cancer-related psychological distress, including some as a proxy for anxiety (e.g., Antoni et al., 2006; Baider \& De-Nour, 1997; Devine, Parker, Fouladi, \& Cohen, 2003; Dupont, Bower, Stanton, \& Ganz, 2014; Johnson Vickberg, Bovbjerg, DuHamel, Currie, \& Redd, 2000; Lepore \& Helgeson, 1998; Lerman et al., 1995; Macefield et al., 2010). The items were as follows: 'Any reference to prostate cancer brought up strong feelings in me', 'I thought about prostate cancer even though I didn't mean to', 'Just hearing the words 'prostate cancer' scared me', 'Other things kept making me think about prostate cancer', and 'I had more trouble falling asleep because I couldn't get thoughts of prostate cancer out of my mind'. Participants were asked to indicate how frequently they experienced these symptoms in the past week and response options were 'not at all' (0), 'rarely' (1), 'sometimes' (2), or 'often' (3). The five items were averaged at Time $1(\alpha=.82)$ and Time $2(\alpha=.82)$.

\section{Test-result anxiety}

As a measure of anxiety about the test result specifically, we used one item from the MAX-PC (Roth et al., 2003), 'I am afraid that the results from my PSA test will show that I have prostate cancer'. Participants could respond to this statement with the options 'not at all' (0), 'rarely' (1), 'sometimes' (2), or 'often' (3). They answered the question at Time 1 and Time 2.

\section{Knowledge}

At Time 2, participants completed a test of information that had been presented in the decision aid they had received. The eight questions were adapted from a survey developed for use with newly diagnosed prostate cancer patients in the state of Michigan (Holmes-Rovner, 2005) and from a prostate cancer decision quality measure (Sepucha et al., 2011; also see Lee et al., 2010). Many of the questions were about the benefits and risks of prostate cancer treatments. Examples include, 'With treatment, about how many men diagnosed with early-stage prostate cancer will eventually die of prostate cancer?', and 'For most men with early-stage prostate cancer, how much would waiting 4 weeks to make a treatment decision affect their chances of survival?'. All questions were multiple-choice format. Participants' responses were scored as correct (coded as 1 ) or incorrect (0), and were then averaged for a knowledge score $(\alpha=.70)$.

\section{Treatment openness}

At Time 2, participants answered six questions related to their openness to potential treatments if they should receive a cancer diagnosis. Participants were told, 'Although you may not have cancer, we would like to know what treatment you think you might have if 
you were to have prostate cancer'. Participants were then presented with a list of treatments (surgery, external beam radiation, brachytherapy, watchful waiting, adjuvant hormone therapy, and experimental therapies such as cryotherapy) and answered yes (coded as 1) or no (0) to each treatment. Participants could select 'yes' to multiple treatments, and they could decline to answer.

\section{Analytic strategy}

The following analyses were conducted for both intrusive thoughts and test-result anxiety. To examine change in anxiety from Time 1 to Time 2, we used general linear model repeated-measures analysis of variance (ANOVA) with Time as a within-subjects factor with two levels: Time 1 intrusive thoughts/test-result anxiety and Time 2 intrusive thoughts/test-result anxiety. To examine associations with knowledge, we first examined the bivariate correlations between the anxiety measures and knowledge. We then conducted hierarchical linear regressions in which Time 1 anxiety was entered in Step 1 and Time 2 anxiety was entered in Step 2. Because this analysis tests the ability of the residuals of anxiety at Time 2 in predicting knowledge, it may be interpreted as an association between change in anxiety and knowledge (Cohen, Cohen, West, \& Aiken, 2003). Analyses followed the same method of entry to examine associations with openness to treatment variables except logistic regression was used because these variables were coded dichotomously. Logistic regression was also used to test anxiety $\times$ knowledge interactions on openness to treatment variables.

\section{Results}

\section{Descriptives}

Descriptive analyses showed that, on average, participants answered about one-half of the knowledge questions correctly $(M=0.52, S D=0.27)$. Of treatment options, participants were most open to surgery $(42 \%$ said yes; $S D=0.50)$ and least open to experimental therapies $(21 \% ; S D=0.41)$. Approximately $39 \%$ of participants said 'yes' to only one treatment, $38 \%$ said 'yes' to more than one treatment (the majority of these said 'yes' to two treatments), 15\% said 'no' to all treatments, and the remaining $8 \%$ declined to answer.

Table 1 presents the correlations between intrusive thoughts and test-result anxiety at Time 1 and Time 2, knowledge, and openness to treatments. Intrusive thoughts at Time 1 and Time 2 were significantly correlated, $r=.71, p<.001$, as was test-result anxiety at Time 1 and Time $2, r=.45, p<.001 .^{4}$ Not surprisingly, the two measures of anxiety were positively correlated with each other at both time points. Both measures were negatively associated with knowledge. While neither anxiety measure at Time 1 was associated with openness to the treatment options, both measures at Time 2 were positively associated with openness to surgery. Time 2 test-result anxiety was also positively associated with openness to experimental therapies.

\footnotetext{
${ }^{4}$ To test for multicollinearity in knowledge analyses, we examined the variance inflation factors. The values were I.00 and I.25 for test-result anxiety, and 1.00 and 2.03 for intrusive thoughts, suggesting no multicollinearity issue. For the analyses with treatment options, we examined the two highest correlations and then conducted regressions in steps (first examining Time I as the only predictor, and then adding Time 2) to see whether the standard errors changed significantly. The analyses showed no multicollinearity issue.
} 


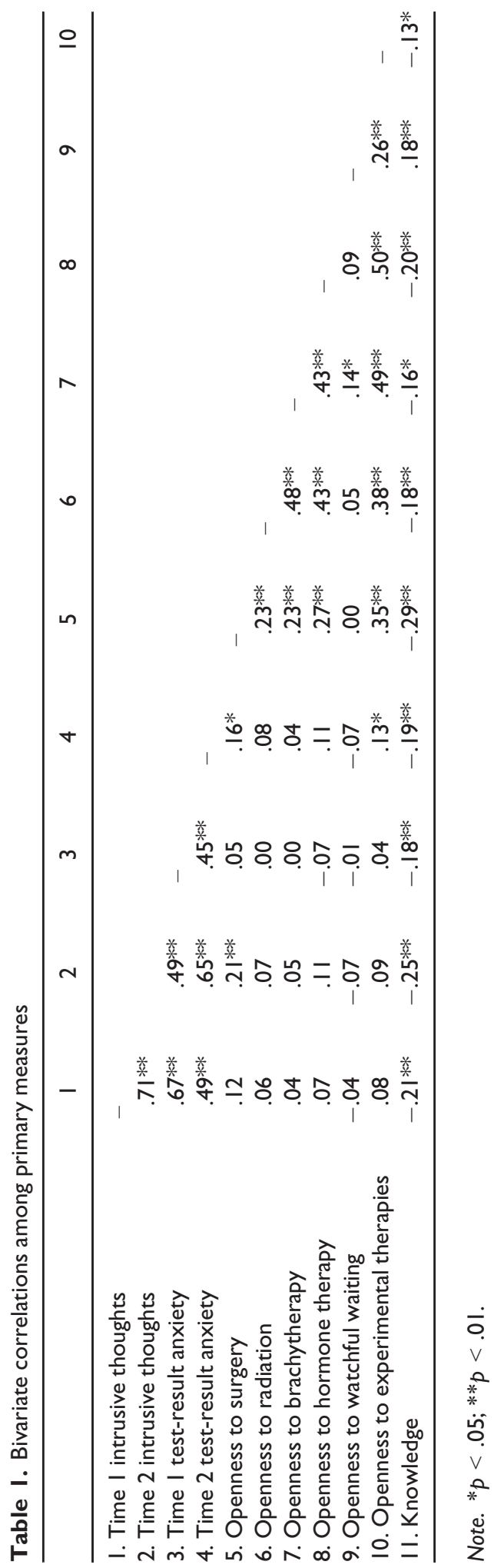




\section{Primary analyses}

Change in anxiety from Time I to Time 2

Repeated-measures ANOVAs were conducted to test whether participants' reports of anxiety at Time 2 increased from their reports of anxiety at Time 1 . For intrusive thoughts, results showed that participants reported greater symptoms at Time 2 ( $M=1.11$, $S D=0.78)$ compared to Time $1(M=1.01, S D=0.77)$, and this difference was significant, $F(1,263)=6.68, p=.01, d=.12$. Test-result anxiety was also significantly higher at Time $2(M=1.17, S D=1.12)$ than Time $1(M=0.97, S D=1.06), F$ $(1,263)=8.77, p=.003, d=.19$. Together, these findings show that as participants came closer to receiving their feedback, both their intrusive thoughts about cancer and their anxiety about their test result significantly increased.

\section{Association between anxiety and knowledge}

We next used linear regression to examine whether Time 2 anxiety was associated with knowledge, while controlling for Time 1 anxiety. Recall, we were testing the hypothesis that higher anxiety would be associated with lower knowledge. Analyses showed that Time 2 intrusive thoughts were significantly, negatively associated with knowledge, $\beta=-.21, t(252)=-2.36, p=.02$. This anxiety explained a significant proportion of variance in knowledge, $R^{2}=.06$, change in $F(1,252)=5.54, p=.02$. The findings for test-result anxiety were similar such that there was a significant, negative association with knowledge, $\beta=-.14, t(252)=-2.00, p<.05$, and the change in variance was significant, $R^{2}=.05$, change in $F(1,252)=3.99, p<.05$. Thus, across both measures, higher anxiety right before learning one's diagnosis was associated with less knowledge of the risks and benefits of the treatment options.

\section{Association between anxiety and treatment openness}

To test the hypothesis that an increase in anxiety would be associated with openness to different types of treatments, logistic regressions were conducted for the six treatments. Table 2 presents the regression coefficients for all of these analyses. The findings revealed that higher intrusive thoughts and test-result anxiety at Time 2 were significantly associated with greater openness to surgery. Higher testresult anxiety was also significantly associated with greater openness to hormone therapy, and marginally significantly associated with greater openness to experimental therapies.

\section{Secondary analyses}

\section{Interactions of anxiety and knowledge on treatment openness}

Logistic regressions were conducted to examine whether anxiety (i.e., intrusive thoughts or test result) and knowledge interacted to influence treatment openness. For these analyses, we first computed a continuous change score of anxiety by subtracting Time 1 anxiety from Time 2 anxiety. We then centred these change scores and participants' knowledge scores. To create the interaction terms, the centred anxiety change scores were multiplied by the centred knowledge scores. In Step 1 of the regressions, the centred anxiety and knowledge scores were entered, and in Step 2 of the regressions, the interaction terms were entered. 
Table 2. Openness to treatments as a function of change in intrusive thoughts and test-result anxiety

\begin{tabular}{|c|c|c|c|c|c|}
\hline Independent variables & B & SE & Wald & Sig & $\operatorname{Exp}(B)$ \\
\hline \multicolumn{6}{|l|}{ Openness to surgery } \\
\hline Time I intrusive thoughts & -0.13 & 0.24 & 0.30 & .59 & 0.88 \\
\hline Time 2 intrusive thoughts & 0.63 & 0.24 & 7.16 & .01 & $1.89 * *$ \\
\hline Overall model & & & 11.28 & .00 & \\
\hline Time I test-result anxiety & -0.05 & 0.14 & 0.13 & .72 & 0.95 \\
\hline Time 2 test-result anxiety & 0.31 & 0.13 & 5.53 & .02 & $1.36^{*}$ \\
\hline Overall model & & & 6.23 & .04 & \\
\hline \multicolumn{6}{|c|}{ Openness to external beam radiation } \\
\hline Time I intrusive thoughts & 0.06 & 0.23 & 0.06 & .81 & 1.06 \\
\hline Time 2 intrusive thoughts & 0.13 & 0.23 & 0.32 & .57 & 1.14 \\
\hline Overall model & & & 1.15 & .56 & \\
\hline Time I test-result anxiety & -0.07 & 0.14 & 0.29 & .59 & 0.93 \\
\hline Time 2 test-result anxiety & 0.18 & 0.13 & 1.90 & .17 & 1.20 \\
\hline Overall model & & & 1.91 & .38 & \\
\hline \multicolumn{6}{|l|}{ Openness to brachytherapy } \\
\hline Time I intrusive thoughts & 0.03 & 0.24 & 0.02 & .90 & 1.03 \\
\hline Time 2 intrusive thoughts & 0.10 & 0.24 & 0.19 & .67 & I.II \\
\hline Overall Model & & & 0.56 & .76 & \\
\hline Time I test-result anxiety & -0.04 & 0.14 & 0.08 & .78 & 0.96 \\
\hline Time 2 test-result anxiety & 0.10 & 0.14 & 0.51 & .48 & 1.10 \\
\hline Overall model & & & 0.51 & .78 & \\
\hline \multicolumn{6}{|l|}{ Openness to hormone therapy } \\
\hline Time I intrusive thoughts & -0.03 & 0.27 & 0.01 & .91 & 0.97 \\
\hline Time 2 intrusive thoughts & 0.33 & 0.27 & 1.51 & .22 & 1.39 \\
\hline Overall model & & & 2.72 & .26 & \\
\hline Time I test-result anxiety & -0.32 & 0.17 & 3.76 & .05 & 0.72 \\
\hline Time 2 test-result anxiety & 0.37 & 0.16 & 5.64 & .02 & $1.44 * *$ \\
\hline Overall model & & & 6.83 & .03 & \\
\hline \multicolumn{6}{|l|}{ Openness to watchful waiting } \\
\hline Time I intrusive thoughts & 0.04 & 0.24 & 0.02 & .88 & 1.04 \\
\hline Time 2 intrusive thoughts & -0.21 & 0.24 & 0.75 & .39 & 0.82 \\
\hline Overall model & & & 1.19 & .55 & \\
\hline Time I test-result anxiety & 0.05 & 0.14 & 0.13 & .72 & 1.05 \\
\hline Time 2 test-result anxiety & 0.16 & 0.13 & 1.43 & .23 & 0.85 \\
\hline Overall model & & & 1.48 & .48 & \\
\hline \multicolumn{6}{|c|}{ Openness to experimental therapies } \\
\hline Time I intrusive thoughts & 0.27 & 0.28 & 0.95 & .33 & 1.31 \\
\hline Time 2 intrusive thoughts & -0.02 & 0.28 & 0.00 & .96 & 0.98 \\
\hline Overall model & & & 1.78 & .41 & \\
\hline Time I test-result anxiety & -0.04 & 0.16 & 0.06 & .80 & 0.96 \\
\hline Time 2 test-result anxiety & 0.31 & 0.16 & 3.77 & .05 & $1.36^{\dagger}$ \\
\hline Overall model & & & 4.28 & .12 & \\
\hline
\end{tabular}

Note. All Time 2 statistics control for Time I.

$* p<.05 ; * * p<.01 ;{ }^{\dagger} p<.10$.

Analyses revealed that intrusive thoughts and knowledge did not interact to influence any of the openness to treatment variables. However, test-result anxiety interacted with knowledge to influence openness to three treatments: surgery, $B=-1.70$, OR $=0.18$, 


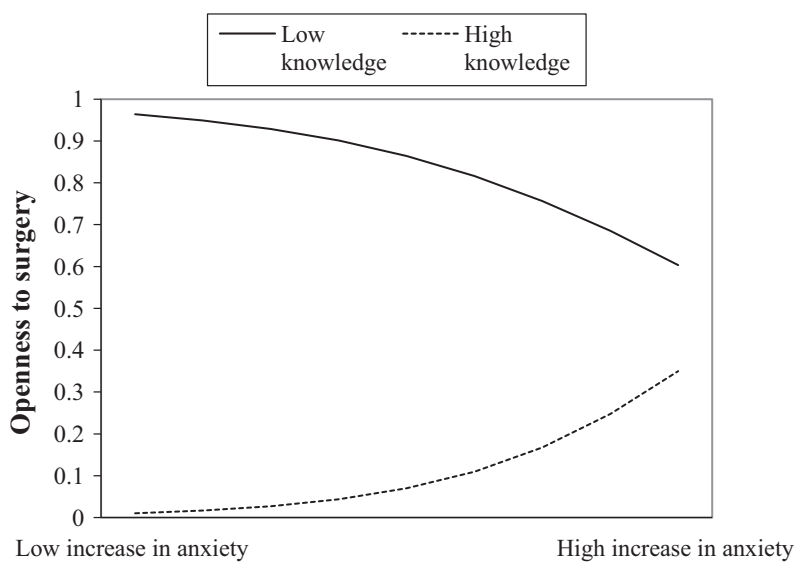

Figure I. Test-result anxiety $\times$ Knowledge on openness to surgery (with higher numbers representing greater openness). Note that 'low increase in anxiety' represents little to no increase in anxiety as well as a decrease from Time I to Time 2.

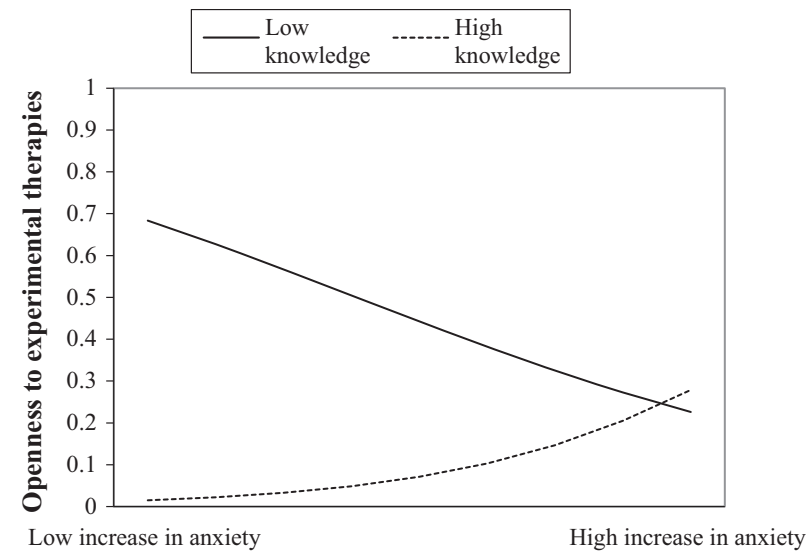

Figure 2. Test-result anxiety $\times$ Knowledge on openness to experimental therapies (with higher numbers representing greater openness).

$p=.003$, experimental therapies, $B=-1.31, \mathrm{OR}=0.27, p=.03$, and radiation, $B=-0.99$, OR $=0.37, p=.04$. Figures $1-3$ present the graphs of these interactions. The pattern was similar across the three openness variables: When participants showed little to no increases in anxiety from Time 1 to Time 2, having low knowledge relative to high knowledge was associated with being more open to each treatment. However, when participants showed high increases in anxiety across the time points, having low or high knowledge was less likely to show these differences in openness.

\section{Discussion}

In the present study, men's symptoms of anxiety increased as they came closer to receiving feedback of whether they had prostate cancer. Higher anxiety was significantly associated with less knowledge about prostate cancer and greater openness to particular 


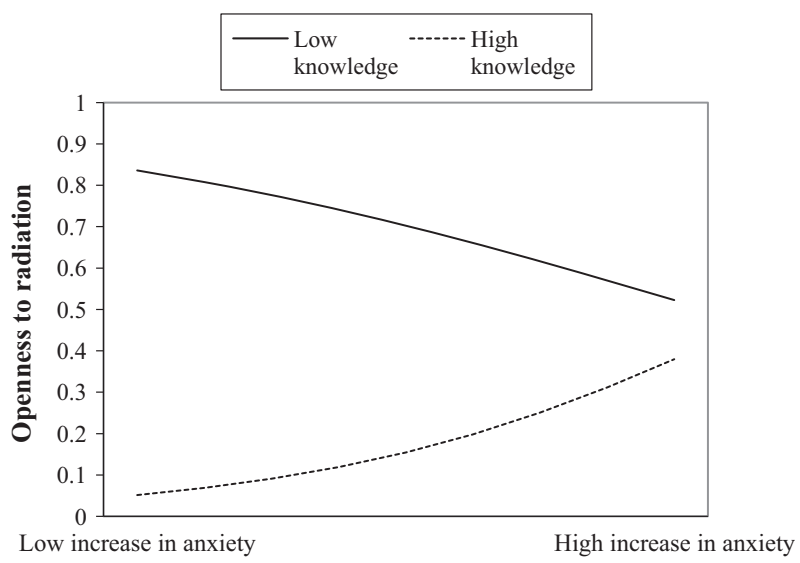

Figure 3. Test-result anxiety $\times$ Knowledge on openness to radiation (with higher numbers representing greater openness).

treatments like surgery. Secondary analyses further showed that anxiety interacted with knowledge in associations with openness to the different treatments. These findings provide insight into the trajectory of anxiety as well its associations as individuals wait for serious health feedback.

From the time they first presented for their prostate biopsy to the time, about 1 month later, when they returned to learn their results, men increased in self-reported anxiety. Although the overall increase was small, it was significant across two measures of anxiety including intrusive thoughts about prostate cancer and anxiety about the test result. Because normative prevalence data of anxiety symptoms in men at-risk for prostate cancer do not exist (Dale et al., 2005), it is difficult to determine how 'normal' the levels of symptoms in our participants were. In fact, our findings not only contribute to a small area of research but also to an area of mixed results: To date, studies have found evidence of both low and high anxiety in men undergoing prostate cancer screening (e.g., Carlsson et al., 2007; Dale et al., 2005). Our findings show that anxiety may change while waiting for a diagnosis, suggesting it is important to measure symptoms at more than one time point during the screening process.

At both time points and across two measures, higher anxiety was significantly correlated with less knowledge. Higher order analyses then showed that increased anxiety symptoms were significantly associated with lower knowledge. These findings fit with previous experimental research showing that negative affective states lead to less attention and comprehension of information (e.g., Raghunathan \& Pham, 1999). Given this previous work, one interpretation of our study's findings is that anxiety led participants to pay less attention to the information in the decision aid. This interpretation would also fit with theoretical perspectives that suggest that negative affect biases information processing in predictable ways. For example, according to the affect as a spotlight model (Peters, Lipkus, \& Diefenbach, 2006), when individuals are making a health decision, their anxiety about different options acts as a spotlight, leading them to give greater attention to some information and less attention to other information. This selective processing ultimately favours the option the individual has the least anxiety about. While this theory and research may support the idea that anxiety inhibited information processing, our study was correlational. Thus, alternative interpretations 
cannot be ruled out. For example, one possibility is that having lower knowledge caused anxiety. Although all participants reported reading the decision aid, some may not have given it their complete attention or had difficulty understanding the information. Then, because of their low knowledge, they increased in anxiety.

Increased anxiety was also associated with greater openness to the treatments of surgery, hormone therapy, and experimental therapies. Because in prostate cancer treatment decisions, there is no best treatment, these associations are difficult to interpret. It could be that higher anxiety increased openness to treatments like surgery and experimental therapies because these treatments are perceived as action-oriented (e.g., Chapple et al., 2002). While the converse association with watchful waiting was consistent with this idea, it was not significant. Although interpreting these associations requires further research, the findings are meaningful if only to show that anxiety during this time period is related to treatment openness. To the extent that this openness leads to preferences, actual treatment decisions could be affected (e.g., Denberg et al., 2006).

Some of the associations above were qualified by interactions. For example, when participants' anxiety about their test result showed little to no increase from Time 1 to Time 2, having high knowledge was associated with being less open to the different treatments. However, when they increased in anxiety from Time 1 to Time 2, having higher or lower knowledge was not distinctly related to openness. While these findings are consistent with interactions found in other studies of cancer anxiety, knowledge, and behaviour (Cameron \& Reeve, 2006; Dillard et al., 2013), the present study is the first to show this interaction in the context of prostate cancer. Together, these studies suggest that cancer anxiety may motivate behaviour, but not through increased knowledge.

\section{Implications and future directions}

Our finding that anxiety increased as individuals came closer to receiving feedback about a cancer diagnosis replicates one study in the area of prostate cancer (e.g., Zisman et al., 2001) and several in the area of breast cancer (e.g., Benedict, Williams, \& Baron, 1994; Keyzer-Dekker, de Vries, Mertens, Roukema, \& van der Steeg, 2014; Lang, Berbaum, \& Lutgendorf, 2009; Lang et al., 2006; Liao et al., 2008). Some researchers have recommended shortening the anticipation period between biopsy and result disclosure. In further showing that anxiety at this time may be associated with worse knowledge, the present study strengthens this recommendation.

One question for future research is why was knowledge negatively associated with openness to all of the treatments except watchful waiting? These associations could possibly indicate a general relationship between knowledge and preference for treatments. For example, it is possible that people who are more knowledgeable feel more comfortable taking a 'wait and see' approach while those with less knowledge are more eager to have action-oriented treatment. Familiarity may also play a role in these associations. A treatment like surgery may seem familiar to people and thereby those with less knowledge are more open to that treatment.

To provide more insight into anxiety's relationship with knowledge, future studies should integrate more comprehensive measures. Amount of effort used to learn information might be one such measure. Also, assessing knowledge at multiple time points may provide insight as to when anxiety influences knowledge (e.g., during initial information processing or recall of information, or both?). 


\section{Limitations}

The correlational design of the present study is a limitation, and future research should attempt to determine the causal direction of the observed associations. One caveat is that true experimental designs in contexts similar to the present study may be difficult or impossible. For example, as people wait for a cancer diagnosis, it may not be ethical to randomly assign them to have more versus less knowledge to then determine the effects on anxiety. Similarly, this time period is not one in which researchers would want to increase anxiety to then determine what happens to information processing. However, experimental research in a hypothetical cancer feedback context could shed light on our correlational findings.

Another limitation related to the correlational design is that unmeasured variables could have played a role in our findings. For example, we did not measure trait anxiety which can relate to anxiety about cancer and information processing (Bar-Haim, Lamy, Pergamin, Bakermans-Kranenburg, \& van IJzendoorn, 2007; Keyzer-Dekker et al., 2014).

\section{Conclusion}

In the present study, as men waited for a prostate cancer diagnosis, they increased in both intrusive thoughts about prostate cancer and anxiety about their test result. Increased anxiety was associated with lower knowledge and more openness to particular treatments. Some of these associations were qualified by interactions showing that when anxiety increased, knowledge was not systematically connected to treatment openness. This study highlights the need for more research on specific negative emotions and their implications in individuals waiting for diagnoses.

\section{Acknowledgements}

Financial support for this study was provided by an IIR Merit Award from US Department of Veterans Affairs (IIR 05-283) to Dr. Fagerlin. The decision aids used in the study were provided free of charge by the producers of the tools (Michigan Cancer Consortium provided the plain language decision aid, and the American Cancer Society provided the higher literacy decision aid). However, neither organization had any input in the research project. In fact, all funding agreements ensured the authors' independence in designing the study, interpreting the data, and publishing the report.

\section{Conflict of interest}

All authors declare no conflict of interest.

\section{References}

Antoni, M. H., Wimberly, S. R., Lechner, S. C., Kazi, A., Sifre, T., Urcuyo, K. R., . . Carver, C. S. (2006). Stress management intervention reduces cancer-specific thought intrusions and anxiety symptoms among women undergoing treatment for breast cancer. American Journal of Psychiatry, 163, 1791-1797. doi:10.1176/appi.ajp.163.10.1791

Awsare, N. S., Green, J. S. A., Aldwinckle, B., Hanbury, D. C., Boustead, G. B., \& McNicholas, T. A. (2008). The measurement of psychological distress in men being investigated for the presence of prostate cancer. Prostate Cancer and Prostatic Diseases, 11, 384-389. doi:10.1038/ pcan.2008.21 
Baider, L., \& De-Nour, A. K. (1997). Psychological distress and intrusive thoughts in cancer patients. The Journal of Nervous and Mental Disease, 185, 346-348. doi:10.1097/00005053-19970 5000-00010

Bar-Haim, Y., Lamy, D., Pergamin, L., Bakermans-Kranenburg, M. J., \& van IJzendoorn, M. H. (2007). Threat-related attentional bias in anxious and nonanxious individuals: A meta-analytic study. Psychological Bulletin, 133, 1-24. doi:10.1037/0033-2909.133.1.1

Benedict, S., Williams, R. D., \& Baron, P. L. (1994). Recalled anxiety: From discovery to diagnosis of a benign breast mass. Oncology Nursing Forum, 21, 1723-1727.

Brindle, L. A., Oliver, S. E., Dedman, D., Donovan, J. L., Neal, D. E., Hamdy, F. C., . . Peters, T. J. (2006). Measuring the psychosocial impact of population-based prostate-specific antigen testing for prostate cancer in the UK. BJU International, 98, 777-782. doi:10.1111/j.1464410X.2006.06401.x

Burgess, C., Cornelius, V., Love, S., Graham, J., Richards, M., \& Ramirez, A. (2005). Depression and anxiety in women with early breast cancer: Five year observational cohort study. British Medical Journal, 330, 702-706. doi:10.1136/bmj.38343.670868.D3

Cameron, L., \& Reeve, J. (2006). Risk perceptions, worry, and attitudes about genetic testing for breast cancer susceptibility. Psychology and Health, 21, 211-230. doi:10.1080/ 14768320500230318

Carlsson, S., Aus, G., Wessman, C., \& Hugosson, J. (2007). Anxiety associated with prostate cancer screening with special reference to men with a positive screening test (elevated PSA) - Results from a prospective, population-based, randomised study. European Journal of Cancer, 43, 2109-2116. doi:10.1016/j.ejca.2007.06.002

Chapple, A., Ziebland, S., Herxheimer, A., McPherson, A., Shepperd, S., \& Miller, R. (2002). Is 'watchful waiting' a real choice for men with prostate cancer? A qualitative study. BJU International, 90, 257-264. doi:10.1046/j.1464-410X.2002.02846.x

Cohen, J., Cohen, P., West, S. G., \& Aiken, L. S. (2003). Applied multiple regression/correlation analysis in the behavioral sciences (3rd ed.). Mahwah, NJ: Erlbaum.

Consedine, N. S. (2012). Are we worrying about the right men and are the right men feeling worried? Conscious but not unconscious prostate anxiety predicts screening among men from three ethnic groups. American Journal of Men's Health, 6, 37-50. doi:10.1177/ 1557988311415513

Conway, M., \& Giannopoulos, C. (1993). Dysphoria and decision making: Limited information use for evaluations of multiattribute targets. Journal of Personality and Social Psychology, 64, 613623. doi:10.1037/0022-3514.64.4.613

Cormier, L., Valeri, A., Azzouzi, R., Fournier, G., Cussenot, O., Berthon, P., \& ... Mangin, P., (2002). Worry and attitude of men in at-risk families for prostate cancer about genetic susceptibility and genetic testing. Prostate, 51, 276-285. doi:10.1002/pros.10092

Dale, W., Bilir, P., Han, M., \& Meltzer, D. (2005). The role of anxiety in prostate carcinoma: A structured review of the literature. Cancer, 104, 467-478. doi:10.1002/cncr.21198

Denberg, T. D., Melhado, T. V., \& Steiner, J. F. (2006). Patient treatment preferences in localized prostate carcinoma: The influence of emotion, misconception, and anecdote. Cancer, 107, 620 630. doi:10.1002/cncr.22033

Devine, D., Parker, P. A., Fouladi, R. T., \& Cohen, L. (2003). The association between social support, intrusive thoughts, avoidance, and adjustment following an experimental cancer treatment. Psychooncology, 12, 453-462. doi:10.1002/pon.656

Dillard, A. J., Scherer, L., Ubel, P. A., Smith, D. M., Zikmund-Fisher, B. J., McCLure, J. B., . . Fagerlin, A. (2013). Effects of breast cancer anxiety on risk perception, knowledge, and behavioral intentions in a breast cancer chemoprevention decision. Social Science \& Medicine, 77, 13-19. doi:10.1016/j.socscimed.2012.10.009

Dupont, A., Bower, J. E., Stanton, A. L., \& Ganz, P. A. (2014). Cancer-related intrusive thoughts predict behavioral symptoms following breast cancer treatment. Health Psychology, 33, 155-163. doi:10.1037/a0031131 
Edwards, B., \& Clarke, V. (2004). The psychological impact of a cancer diagnosis on families: The influence of family functioning and patients' illness characteristics on depression and anxiety. Psycho-Oncology, 13, 562-576. doi:10.1002/pon.773

Essink-Bot, M. L., de Koning, H. J., Nijs, H. G., Kirkels, W. J., van der Maas, P. J., \& Schroder, F. H. (1998). Short-term effects of population-based screening for prostate cancer on health-related quality of life. Journal of the National Cancer Institute, 90, 925-931. doi:10.1093/jnci/ 90.12.925

Fagerlin, A., Holmes-Rovner, M., Hofer, T. P., Rovner, D., Alexander, S. C., Knight, S. J., . . Ubel, P. A. (2015). Do decision aids matter? Randomized controlled test of a plain language decision aid vs. higher literacy decision aid for prostate cancer patients. Manuscript submitted for publication.

Fantini-Hauwel, C., Dauvier, B., Arciszewski, T., Antoine, P., \& Manouvrier, S. (2011). Genetic testing for hereditary cancer: Effects of alexithymia and coping strategies on variations in anxiety before and after result disclosure. Psychology and Health, 26, 855-873. doi:10.1080/ 08870446.2010 .506575

Gustafsson, O., Theorell, T., Norming, U., Perski, A., Ohstrom, M., \& Nyman, C. R. (1995). Psychological reactions in men screened for prostate cancer. British Journal of Urology, 75, 631-636. doi:10.1111/j.1464-410x.1995.tb07422.x

Holmes-Rovner, M. (2005). Likely consequences of increased patient choice. Health Expectations, 8 (1), 1-3. doi:10.1111/j.1369-7625.2004.00314.x

Horowitz, M. J. (1986). Stress-response systems: A review of posttraumatic and adjustment disorders. Hospital \& Community Psychiatry, 37, 241-249. doi:10.1176/ps.37.3.241

Horowitz, M., Wilner, N., \& Alvarez, W. (1979). Impact of event scale-measure of subjective stress. Psychosomatic Medicine, 41, 209-218. doi:10.1097/00006842-197905000-00004

Hughes, J. (1982). Emotional reactions to the diagnosis and treatment of early breast cancer.Journal of Psychosomatic Research, 26, 277-283. doi:10.1016/0022-3999(82)90047-2

Johnson Vickberg, S. M., Bovbjerg, D. H., DuHamel, K. N., Currie, V., \& Redd, W. H. (2000). Intrusive thoughts and psychological distress among breast cancer survivors: Global meaning as a possible protective factor. Behavioral Medicine, 25, 152-162. doi:10.1080/08964280009595744

Keyzer-Dekker, C. M. G., de Vries, J., Mertens, M. C., Roukema, J. A., \& van der Steeg, A. F. W. (2014). The impact of diagnosis and trait anxiety on psychological distress in women with early stage breast cancer: A prospective study. British Journal of Health Psychology, 19, 783-794. doi:10.1111/bjhp. 12076

Lang, E. V., Berbaum, K. S., Faintuch, S., Hatsiopoulou, O., Halsey, N., Li, X., .. Baum, J. (2006). Adjunctive self-hypnotic relaxation for outpatient medical procedures: A prospective randomized trial with women undergoing large core breast biopsy. Pain, 126, 155-164. doi:10.1016/j.pain.2006.06.035

Lang, E. V., Berbaum, K. S., \& Lutgendorf, S. K. (2009). Large-core breast biopsy: Abnormal salivary cortisol profiles associated with uncertainty of diagnosis. Radiology, 250, 631-637. doi:10.1148/radiol.2503081087

Lee, C. N., Dominik, R., Levin, C. A., Barry, M. J., Cosenza, C., O'Connor, A. M., ... Sepucha, K. R. (2010). Development of instruments to measure the quality of breast cancer treatment decisions. Health Expectations, 13, 258-272. doi:10.1111/j.1369-7625.2010.00600.x

Lepore, S. J., \& Helgeson, V. S. (1998). Social constraints, intrusive thoughts, and mental health after prostate cancer. Journal of Social and Clinical Psychology, 17, 89-106. doi:10.1521/ jscp.1998.17.1.89

Lerman, C., Seay, J., Balshem, A., \& Audrain, J. (1995). Interest in genetic testing among first-degree relatives of breast-cancer patients. American Journal of Medical Genetics, 57, 385-392. doi:10.1002/ajmg.1320570304

Lewinsohn, S., \& Mano, H. (1993). Multiattribute choice and affect - the influence of naturallyoccurring and manipulated moods on choice processes. Journal of Behavioral Decision Making, 6, 33-51. doi:10.1002/bdm.3960060103 
Liao, M. N., Chen, M. F., Chen, S. C., \& Chen, P. L. (2008). Uncertainty and anxiety during the diagnostic period for women with suspected breast cancer. Cancer Nursing, 31, 274-283. doi:10.1097/01.NCC.0000305744.64452.fe

Linden, W., Vodermaier, A., MacKenzie, R., \& Greig, D. (2012). Anxiety and depression after cancer diagnosis: Prevalence rates by cancer type, gender, and age. Journal of Affective Disorders, 141 , 343-351. doi:10.1016/j.jad.2012.03.025

Macefield, R. C., Lane, J. A., Metcalfe, C., Down, L., Neal, D. E., Hamdy, F. C., \& Donovan, J. L. (2009). Do the risk factors of age, family history of prostate cancer or a higher prostate specific antigen level raise anxiety at prostate biopsy? European Journal of Cancer, 45, 2569-2573. doi:10.1016/j.ejca.2009.03.016

Macefield, R. C., Metcalfe, C., Lane, J. A., Donovan, J. L., Avery, K. N. L., Blazeby, J. M., ... Vedhara, K. (2010). Impact of prostate cancer testing: An evaluation of the emotional consequences of a negative biopsy result. British Journal of Cancer, 102, 1335-1340. doi:10.1038/sj.bjc.6605648

Maxwell, J. R., Bugbee, M. E., Wellisch, D. K., Shalom, A., Sayre, J., \& Bassett, L. W. (2000). Imageguided core needle biopsy of the breast: Study of psychological outcomes. The Breast Journal, 6, 53-61. doi:10.1046/j.1524-4741.2000.98079.x

McCaul, K., Schroeder, D., \& Reid, P. (1996). Breast cancer worry and screening: Some prospective data. Health Psychology, 15, 430-433. doi:10.1037/0278-6133.15.6.430

McQueen, A., Vernon, S. W., Meissner, H. I., \& Rakowski, W. (2008). Risk perceptions and worry about cancer: Does gender make a difference? Journal of Health Communication, 13, 56-79. doi:10.1080/10810730701807076

Medd, J. C., Stockler, M. R., Collins, R., \& Lalak, A. (2005). Measuring men's opinions of prostate needle biopsy. ANZ Journal of Surgery, 75, 662-664. doi:10.1111/j.1445-2197.2005.03477.x

Peters, E., Lipkus, I., \& Diefenbach, M. A. (2006). The functions of affect in health communications and in the construction of health preferences. The Journal of Communication, 56, S140-S162. doi:10.1111/j.1460-2466.2006.00287.x

Pickles, T., Ruether, J. D., Weir, L., Carlson, L., Jakulj, F., \& the SCRN Communication Team (2007). Psychosocial barriers to active surveillance for the management of early prostate cancer and a strategy for increased acceptance. BJU International, 100, 544-551. doi:10.1111/j.1464410X.2007.06981.x

Poole, K. (1997). The emergence of the 'waiting game': A critical examination of the psychosocial issues in diagnosing breast cancer. Journal of Advanced Nursing, 25, 273-281. doi:10.1046/ j.1365-2648.1997.1997025273.x

Raghunathan, R., \& Pham, M. (1999). All negative moods are not equal: Motivational influences of anxiety and sadness on decision making. Organizational Behavior and Human Decision Processes, 79, 56-77. doi:10.1006/obhd.1999.2838

Roth, A. J., Rosenfeld, B., Kornblith, A. B., Gibson, C., Scher, H. I., Curley-Smart, T., . . Breitbart, W. (2003). The memorial anxiety scale for prostate cancer: Validation of a new scale to measure anxiety in men with with prostate cancer. Cancer, 97, 2910-2918. doi:10.1002/cncr.11386

Roumier, X., Azzouzi, R., Valeri, A., Guillemin, F., Fournier, G., Cussenot, O., ... Cormier, L., (2004). Adherence to an annual PSA screening program over 3 years for brothers and sons of men with prostate cancer. European Urology, 45, 280-286. doi:10.1016/j.eururo.2003. 09.022

Saegrov, S., \& Halding, A. G. (2004). What is it like living with the diagnosis of cancer? European Journal of Cancer Care, 13, 145-153. doi:10.1097/00006199-198301000-00006

Saraçoğlu, T., Ünsal, A., Taşkın, F., Sevinçok, L., \& Zafer Karaman, C. (2012). The impact of preprocedural waiting period and anxiety level on pain perception in patients undergoing transrectal ultrasound-guided prostate biopsy. Diagnostic and Interventional Radiology, 18, 195-199. doi:10.4261/1305-3825.DIR.4643-11.1

Schwarz, N. (2000). Emotion, cognition, and decision making. Cognition E Emotion, 14, 433-440. doi:10.1080/026999300402745 
Schwarz, N., Bless, H., \& Bohner, G. (1991). Mood and persuasion: Affective states influence the processing of persuasive communications. Advances in Experimental Social Psychology, 24, 161-199.

Scott, D. W. (1983). Anxiety, critical thinking, and information processing during and after breast biopsy. Nursing Research, 32, 3-62. doi:10.1097/00006199-198301000-00006

Sepucha, K., Stacey, D., Clay, C., Chang, Y., Cosenza, C., Dervin, G., . . Levin, C. A. (2011). Decision quality instrument for treatment of hip and knee osteoarthritis: A psychometric evaluation. BMC Musculoskeletal Disorders, 12, 149. doi:10.1186/1471-2474-12-149

Shepperd, J. A., Grace, J., Cole, L. J., \& Klein, C. (2005). Anxiety and outcome predictions. Personality and Social Psychology Bulletin, 31, 267-275. doi:10.1177/0146167204271322

Shepperd, J., Ouellette, J., \& Fernandez, J. (1996). Abandoning unrealistic optimism: Performance estimates and the temporal proximity of self-relevant feedback. Journal of Personality and Social Psychology, 70, 844-855. doi:10.1037/0022-3514.70.4.844

Stanton, A. L., \& Snyder, P. R. (1993). Coping with a breast cancer diagnosis: A prospective study. Health Psychology, 12, 16-33. doi:10.1037/0278-6133.12.1.16

Stark, D. P. H., \& House, A. (2000). Anxiety in cancer patients. British Journal of Cancer, 83, 12611267. doi:10.1054/bjoc.2000.1405

Sweeny, K., \& Andrews, S. E. (2014). Mapping individual differences in the experience of a waiting period. Journal of Personality \& Social Psychology, 106, 1015-1030. doi:10.1037/a0036031

Sweeny, K., \& Cavanaugh, A. G. (2012). Waiting is the hardest part: A model of uncertainty navigation in the context of health news. Health Psychology Review, 6, 147-164. doi:10.1080/ 17437199.2010 .520112

Sweeny, K., \& Shepperd, J. A. (2007). Do people brace sensibly? Risk judgments and event likelihood. Personality and Social Psychology Bulletin, 33, 1064-1075. doi:10.1177/ 0146167207301024

Taylor, K., \& Shepperd, J. (1998). Bracing for the worst: Severity, testing, and feedback timing as moderators of the optimistic bias. Personality and Social Psychology Bulletin, 24, 915-926. doi: $10.1177 / 0146167298249001$

Thorne, S. E., Harris, S. R., Hislop, T. G., \& Vestrup, J. A. (1999). The experience of waiting for diagnosis after an abnormal mammogram. The Breast Journal, 5, 42-51. doi:10.1046/j.15244741.1999.005001042.x

van't Spijker, A., Trijsburg, R. W., \& Duivenvoorden, H. J. (1997). Psychological sequelae of cancer diagnosis: A meta-analytical review of 58 studies after 1980. Psychosomatic Medicine, 59, 280293. doi:10.1097/00006842-199705000-00011

Wade, J., Rosario, D. J., Macefield, R. C., Avery, K. N. L., Salter, C. E., Goodwin, M. L., ... Donovan, J. L. (2013). Psychological impact of prostate biopsy: Physical symptoms, anxiety, and depression. Journal of Clinical Oncology, 45, 4801-4814. doi:10.1200/JCO.2012.45.4801

Zisman, A., Leibovici, D., Kleinmann, J., Siegel, Y. I., \& Lindner, A. (2001). The impact of prostate biopsy on patient well-being: A prospective study of pain, anxiety and erectile dysfunction. Journal of Urology, 165, 445-454. doi:10.1097/00005392-200102000-00023

Received 2I September 2016; revised version received 27 October 2016

\section{Supporting Information}

The following supporting information may be found in the online edition of the article:

Appendix S1. Knowledge questions. 